\title{
Forecasting Industry-Level CPI and PPI Inflation: Does Exchange Rate Pass-Through Matter?*
}

\author{
Prasad S. Bhattacharya ${ }^{\dagger}$ and Dimitrios D. Thomakos
}

December 16, 2003

\begin{abstract}
In this paper, we examine whether industry-level forecasts of CPI and PPI inflation can be improved using the "exchange rate pass-through" effect, that is, when one accounts for the variability of the exchange rate and import prices. An exchange rate depreciation leading to a higher level of pass-through to import prices implies greater expenditure switching, which should be manifested, possibly with a lag, in both producer and consumer prices. We build a forecasting model based on a two or three equation system involving CPI and PPI inflation where the effects of the exchange rate and import prices are taken into account. This setup also incorporates their dynamics, lagged correlations and appropriate restrictions suggested by the theory. We compare the performance of this model with a variety of unrestricted univariate and multivariate time series models, as well as with a model that, in addition, includes standard control variables for inflation, like interest rates and unemployment. Our results indicate that improvements on the forecast accuracy can be effected when one takes into account the possible pass-through effects of exchange rates and import prices on CPI and PPI inflation.
\end{abstract}

${ }^{*}$ An earlier version of this paper was presented at the 23rd International Symposium on Forecasting in Merida, Mexico, 2003. We would like to thank the Symposium participants as well as Prasad Bidarkota, Jonathan Hill, Luis Bernal, and Mehmet A. Ulubasoglu for comments on earlier drafts. All remaining errors are our responsibility.

${ }^{\dagger}$ Corresponding author, e-mail: prasad.bhattacharya@fiu.edu. All authors are with the Department of Economics at Florida International University, Miami, FL 33199. 


\section{Introduction}

Improving out-of-sample (real world) forecasts for domestic inflation is a topic of continuing interest and research. Fildes and Stekler (2002) survey historical accuracy of US and UK inflation forecasts coming from both macro-econometric as well as time series models and identify systematic errors as one of the qualitative failures to achieve accurate prediction. Zarnowitz and Braun (1992) provide evidence of systematic errors in US inflation forecasts and Mills and Pepper (1999) discuss about errors in case of UK inflation forecasts. Suggestions for improving forecast accuracy involve greater use of economic indicators, which are incorporated in earlier studies. For example, Stock and Watson (1999) model US inflation using an indicator based on 168 disaggregate activity indicators and achieve reasonable forecast improvements. Combining both aggregate and disaggregate indicators through Bayesian shrinkage procedures, Zellner and Chen (2001) also report higher forecast accuracy in predicting US real GDP growth. Past studies in the literature also use commodity prices as an economic indicator to achieve forecast improvements, though the results are mixed. For instance, Pecchenino (1992) discusses the conditions under which commodity prices are useful information variables for monetary policy and provides empirical results to suggest that commodity prices may not be very useful for forecasting. Moosa (1998), using consumer prices and four commodity price indices for OECD countries concludes that commodity prices can be used as a leading indicator of inflation although all the characteristics of an "optimal" leading indicator are not verified. Franses and Ooms (1997) consider an extension of the fractionally integrated ARIMA $(0, d, 0)$ model for quarterly UK inflation and allow the fraction integration parameter $(\mathrm{d})$ to vary with the season 's' to get a long-memory model for UK inflation. However, out-of-sample forecasting from this model do not fare better as compared to other autoregressive, periodic autoregressive as well as ARFIMA alternatives. These systematic errors and mixed evidences on inflation forecasts based on economic indicators are therefore not enough to explain the variability of inflation in the industrial countries. As a result, monetary policy makers try to look for some other adjustments in domestic inflation coming from "special factors" like import prices and exchange rates. The 
new open economy macroeconomics literature (Lane (2001) provides an excellent survey on this topic) re-addresses the exchange rate fluctuation and the corresponding price changes issue using intertemporal approaches to open-economy dynamics, the effects of market structure on international trade and Keynesian nominal rigidities. Domestic inflation can be influenced by the extent of exchange rate pass-through effect towards domestic prices. The textbook definition of exchange rate pass-through is the percent change in local currency import prices resulting from a one percent change in the exchange rate between the exporting and importing country. As argued in the local currency pricing (LCP, see Devereux (1997)) or pricing to market (PTM see, Krugman (1987)) mechanisms, maintaining pricing in terms of buyers' or consumers' or importers' currency, the exchange rate pass-through effect to domestic prices of imported goods will be almost nil or zero. On the other hand, pricing assumption in terms of sellers' or exporters' or producers' currency, as conjectured by the producer currency pricing (PCP) models, will lead to a proportionate change in the domestic prices of imported goods after a change in the nominal exchange rate. Obstfeld (2002) and Engel (2002) are two important references that discuss the debate about exchange rate regime choice based on these two contradicting pricing assumption. According to the first view, domestic inflation will be unaffected by the changes in the exchange rate and the related passthrough effect, whereas, the second argument will call for suitable policy adjustment, as exchange rate pass-through will significantly affect the domestic prices. Some studies in the past explore the effect of exchange rate pass-through in predicting inflation. For example, Ball (1999) incorporate the degree of pass-through in the monetary policy rule to control inflation. Kim (1998) employs an vector error correction model to show that exchange rate appreciation has the predictable negative long-run effect on the US PPI. McCarthy (2000) uses a VAR model and impulse responses based on that to examine the impact of exchange rates and import prices on the domestic PPI and CPI for seven industrial countries, which includes Japan, USA and UK. His findings suggest that import prices have much stronger effect than exchange rates in explaining domestic price inflation. This supports other studies like Boldin (1998) and Koenig (1998), which also achieve forecasting improvements after including import prices in a CPI inflation forecasting model. Taylor (2000), 
however, argues that the low level of inflation in the nineties in the US can be one potential explanation of lower pass-through effect or lower pricing power of the firms, thus making exchange rate pass-through endogenous in determining the optimal price level.

In this paper, we take the exchange rate pass-through effect (as an exogenous variable, unlike Taylor (2000)) for predicting the behavior of future domestic prices. Based on the ideas of Obstfeld (2001, 2002), we follow the framework of Bhattacharya et al. (2003), using monthly industry-level price data for USA, UK and Japan that takes not only the pass-through effect to different prices, but also shows that there may be a potential difference in the pass-through effects towards import prices and domestic prices of the imported goods. Obstfeld (2001) builds a theoretical model along this line and Obstfeld (2002) provides empirical evidence for Keynesian-type sticky-price arrangement in terms of sellers' or producers' currencies from US-Canada SITC level data. Bhattacharya et al. (2003) find evidence of PCP to import prices at the point of entry and LCP to domestic prices of imported goods. With the evidence of low pass-through effect towards domestic prices, the domestic inflation will not be much even if there is higher level of pass-through to import prices. Using this structural concept, we do three months ahead out-of-sample inflation forecasting for the industrylevel producer prices (PPI) and consumer prices (CPI). Thereafter, we compare our forecast results from this structural model with forecasts from three different alternative models chosen either based on the data (univariate ARIMA model) or on the simple Philips curve concept (i.e., using unemployment rate and interest rate, the models used are VARs). We also employ some non-linear models based on the property of the price series and forecast future prices from these non-linear alternatives. Our overall results support the structural model incorporating pass-through effect, as it provides the smallest forecast variance as compared to other linear and non-linear models. Therefore, our study points out that we can achieve better inflation forecasts at a very disaggregated price level for consumer prices and producer prices. This has significant policy implication in terms of targeting inflation from the Central Bank's policy perspective. Also, the study provides a pointer for looking at the industry-level future price prediction that can be of help for the sectoral inflation analysis. 
The rest of the paper is organized in the following way. The next section contains two parts. The first part provides a brief description of the simple model of Bhattacharya et al. (2003) that shows the pass-through separation towards import and domestic prices. Thereafter, we briefly discuss the non-linear models used in this study. Section 3 provides the data description used in the analysis. In section 4, we discuss the empirical methodology and a number of in-sample results, including linearity tests. Section 5 presents estimated linear models and their relative forecasting performance. Section 6 contains discussion regarding non-linearity across some price series. The last section concludes with possible extensions to the current work. All tables are given in the first appendix. Model testing results are reported in the second appendix. A third appendix contains details of industry-level import data.

\section{Linear and Non-linear Models}

\section{$2.1 \quad$ A Simple Linear Model}

To put forward the exchange rate pass-through separation (as proposed by Obstfeld $(2001,2002)$ ) from a simple framework, we distinguish between the following four prices: (1) Import prices of foreign goods at the point of entry (denoted by $i m p$ ) (2) Domestic prices of imported goods (denoted by dig) (3) Domestic prices of import-competing goods (denoted by $d d g$ ) (4) Domestic prices, as measured by the CPI (the final price consumers' pay at the point of sale). The $d i g$ and $d d g$ are the constituent parts of CPI. To investigate changes in CPI, we look for changes in either $d d g$ or $d i g$ or in both.

Under the LCP mechanism, neither the dig nor the CPI may change after exchange rate changes. Our simple model of pass-through separation is based on markup adjustments by domestic importers and foreign exporters. With differences in markup adjustments, there may be a difference in pass-through transmission to different prices in the short-run. With PTM, there is proportionate and opposite adjustments in the markups after exchange rate changes resulting in zero or low pass-through. However, with PCP both prices respond proportionately to changes in the exchange 
rate. Different channels of exchange rate pass-through (denoted by (1) and (2), representing two different possibilities) can now be delineated in the following way.

(1) With an unexpected change in the exchange rate (say, due to unanticipated monetary shock), there is pass-through to imp. There may be a potential markup adjustment by foreign exporters at this point (in accordance with the PTM argument proposed by Krugman (1987)). The end result will be either higher or lower pass-through to imp. This is the first and direct pass-through channel.

If the pass-through to imp is fast and of greater magnitude as compared to pass-through to dig and CPI, then there would be changes in relative prices. This is important, for there to be expenditure-switching there has to be a higher level of pass-through to imp but a low pass-through to dig and CPI.

With transaction cost of the imported good added to the domestic price of the imported good, there may be a price difference between $i m p$ and dig. In addition, domestic importers may charge markup on the imported good (price of which is denoted by dig). With different domestic markup adjustment in dig vis-a-vis markup adjustment in imp (as described in (1) above), there may be a relative price difference between dig and imp. Whether CPI changes or not depends on the domestic markup adjustment reflected in dig.

If there is domestic wage rigidity (or price rigidity, as proposed in a number of models, see the related discussion in Bergin (2003) and the references within $)^{1}$, $d d g$ will not change very fast in response to a domestic monetary shock that affects the exchange rate. The exchange rate change will only affect the $i m p .^{2}$

(2) If there is no markup adjustment by foreign exporters at the entry point, the imp will change proportionately with changes in the exchange rate. Since the $d d g$ responds sluggishly, there is a relative price difference between $i m p$ and $d d g$. To maintain the domestic sale of imported goods, domestic importers may adjust the domestic markup in proportion to the $i m p$ hike. This will be

\footnotetext{
${ }^{1}$ Domestic wage rigidity leads to domestic price sluggishness as there may be a wage contract signed before the unexpected monetary shock.

${ }^{2}$ This can happen if invoicing contract is signed a period ahead.
} 
reflected in the $d i g$. This is the mechanism emphasized by LCP or PTM. Thus the $d d g$ and $d i g$ remain at the level before the unanticipated shock. As a result, CPI will not change. This is the second and indirect channel of exchange rate pass-through to dig and CPI.

After all the adjustments taking place as above, there still remains a relative price difference between imp and dig as well as CPI. This may trigger expenditure-switching as is proposed and shown in Obstfeld (2001, 2002) and Obstfeld and Rogoff (2000).

As this discussion suggests, the speed and extent of markup adjustment drives all the results of high and low pass-through to imp and dig as well as CPI.

The second and indirect channel of pass-through to CPI, as described earlier, calls for looking at the extent of domestic markup adjustments. Since we do not have data for the domestic cost of production at the industry-level at monthly frequency therefore, we devise an indirect way to look at this effect. Changes in CPI above reflect changes in either $d d g$ or $d i g$ or both. The dig attributes adjustment at the second stage when the imported good enters the domestic distribution chain. So the exchange rate change at the first stage of entry (reflected in imp) can indirectly capture the change in dig because the second stage adjustment happens if there is there a markup change at the first stage due to changes in the exchange rate. Therefore, we take the exchange rate coefficient as a proxy to the adjustment in dig based on markups. In addition, if there is any change of PPI or CPI due to a change in the dig (assuming that there is tradable component in production), it is possible to separate out that effect. We denote this potential effect as the "carry-over effect". For some industries, the data allows us to look for this effect.

The above discussion calls for data at a very detailed level. Unfortunately, it is difficult to get the industry-level domestic prices of the imported goods. Therefore, we have to make suitable changes in the interpretation. The data we have include (1) consumer prices (CPI)(which reflect prices of final products or final consumer goods), (2) import prices (IMP) for final goods, intermediate goods as well as crude materials and (3) prices for domestic producers (PPI), which can be categorized in terms of final goods, intermediate goods and crude materials. The ability to distinguish in terms 
of end uses provides a better understanding of price movements.

Our setup is such that the exchange rate is exogenously determined and the model focuses on the effect of unexpected changes in the exchange rate. Therefore, we deviate from the traditional exchange rate pass-through estimation literature which typically includes other "control" variables, like a measure of exporters' cost or cost from tariff barriers in the destination country as pointed out in Goldberg and Knetter (1997), which provides a general review of pass-through studies. Import prices for the analysis are exogenously given and these may reflect monopolistically competitive conditions in the exporting country as well as world trade costs. Within this framework, we build three different reduced-form systems to capture the effect of changes in the exchange rate on import prices, producer prices as well as consumer prices.

System I : This setup analyzes various channels which transmit a change in the exchange rate to the final goods prices measured by CPI. The CPI reflects tradable (denoted by dig) and non-tradable goods (denoted by $d d g$ ) prices. With a higher proportion of tradables, any change in the exchange rate that affects their prices would lead to a significant change in CPI. Assuming PCP, the effect will be full. On the other hand, under LCP-PTM mechanism, the extent of the CPI change will be closer to zero.

In this scenario, home retailers import final goods (or tradables) from foreign countries. At the point of entry, retailers pay the price, $P_{r i}$ for foreign exports, which possibly includes a markup $m_{i}^{*} \geq 0$ charged by the exporters. So retailers pay the import price, $P_{r i}$ such that:

$$
P_{r i}=\left(1+m_{i}^{*}\right) E P_{i}^{*}
$$

where $E$ denotes the exchange rate and $P_{i}^{*}$ is the foreign currency price of the i-th good imported in the home country. Depending on whether $m_{i}^{*}$ changes or not, a change in the exchange rate may or may not be reflected in $P_{r i}$. As pointed out earlier, this is the first channel of short-run exchange rate pass-through. Here foreign exporters can price discriminate between destination markets of tradables.

In the home market, the retailers have to bear the transport and distribution costs of final goods 
before selling those to the consumers. Denoting this transaction cost for the i-th good as $\Omega_{r i}$, the total marginal cost that the retailers face is:

$$
M C_{r i}=P_{r i}\left(1+\Omega_{r i}\right)
$$

Letting the domestic markup charged by the retailer to be $\gamma_{i}$, we have the final price of the i-th good as:

$$
P_{c i}=\left(1+\gamma_{i}\right) M C_{r i}
$$

Given (2) and (1), the final price of the i-th good is:

$$
P_{c i}=\left(1+\gamma_{i}\right)\left(1+\Omega_{r i}\right)\left(1+m_{i}^{*}\right) E P_{i}^{*}
$$

where, $P_{c i}$ denotes the final price of the i-th good. Equation (4) shows the link between $E$, import prices and $P_{c i}$ as mediated by the various markups clearly. An import price increase driven by an exchange rate depreciation (assuming no change in foreign mark-up) may or may not lead to a proportional increase in consumer prices. This is the second channel of pass-through. The muted or high response of domestic prices as a result of this import price hike can explained by changes in the existing domestic markup, $\gamma_{i}$ in the way we have described before.

The foreign and domestic markup adjustments can transmit the changes in exchange rate to import prices and domestic prices. These adjustments can be a reflection of sluggish nominal wage adjustments in the foreign country as well as in the home country.

System II : Here, we concentrate on the case where final goods are produced domestically with the help of tradable and non-tradable intermediate inputs. We allow for the possibility that these intermediate inputs themselves have some imported components. Therefore, any change in producer prices of final goods can be explained indirectly by changes in the exchange rate through responsive changes in domestically produced intermediate inputs' prices as well as changes in the prices of imported intermediate inputs.

To capture the underlying structure of System II in terms of the price adjustments, we look at the following expression. In the case where domestic producers use imported intermediate goods, 
the price $\left(P_{n i}\right)$ they pay at the point of entry once the markup $m_{n i}^{*} \geq 0$ charged by the exporters' is taken into account, will be given by:

$$
P_{n i}=\left(1+m_{n i}^{*}\right) E P_{i}^{*}
$$

In addition to the transaction cost, $\Omega_{n i}$, associated with these imported inputs, the producer also has to pay the wage $w_{i}$ per unit of output being produced domestically. Letting $w_{i}$ be the wage rate and let $l_{i}$ denote the unit labor requirement in the production of $\mathrm{i}$-th good. The marginal cost is:

$$
M C_{n i}=P_{n i}\left(1+\Omega_{n i}\right)+w_{i} l_{i}
$$

Taking the domestic markup charged by the producer as $\mu_{i}$, we have the producer price of the i-th good as:

$$
P_{p i}=\left(1+\mu_{i}\right) M C_{n i}
$$

Using (6), we get the producer price of the i-th good as:

$$
P_{p i}=\left(1+\mu_{i}\right)\left[w_{i} l_{i}+\left(1+\Omega_{n i}\right)\left(1+m_{n i}^{*}\right) E P_{i}^{*}\right]
$$

We have a similar interpretation in terms of markup adjustments and producer prices change as before. The expenditure-switching is due to the relative price difference between the imported inputs' prices and producer prices as a result of markup adjustments.

System III : This is similar to System I described earlier, with the difference that the final goods prices are simply replaced by producer prices. In this case, instead of finished retail goods for consumption, we have finished goods for production. As before, denoting the transaction cost for the i-th good by $\Omega_{p i}$, foreign markup by $m_{p i}^{*}$ and the domestic markup charged by the producer by $\nu_{i}$, the producer price of the i-th good will be:

$$
P_{p i}=\left(1+\nu_{i}\right)\left(1+\Omega_{p i}\right)\left(1+m_{p i}^{*}\right) E P_{i}^{*}
$$


The channels through which change in exchange rate is passed through in this system is analogous to the ones described above. What differentiates the three systems is that the pass-through is towards consumer prices in system I and towards producer prices in systems II and III.

\subsection{Non-linear Models: An Appraisal}

Our analysis so far rests on the linearity of price series assumption. However, this may not be necessarily true. As a result, the forecast performance may change from a presumed linear parametric model, whereas the underlying price dynamics may be non-linear. There is a growing literature concentrating on the forecast performance of various linear and non-linear models. Past studies apply a variety of non-linear models like Threshold Autoregressive models ((TAR), see Tong (1990) in particular), Self-Exciting Threshold Autoregressive models ((SETAR), see Franses and van Dijk (2000) for a comprehensive reference), Smooth Transition Autoregressive models ((STAR), see Terasvirta (1994), Granger and Terasvirta (1993) for some useful discussion) and Markov switching models (see, in particular, Hamilton (1989)) for a number of different economic series and compare the forecasts generated from these with simple linear alternative models. For example, Franses and van Dijk (2001) look at 17 OECD countries' quarterly industrial production performance employing a host of seasonal and non-linear models. They find that in general, linear models with fairly simple descriptions of seasonality outperform non-linear models at short forecast horizons, whereas non-linear models with more elaborate seasonal components dominate at longer horizons. This is a fairly established result in forecasting literature, which points the superiority of linear models over non-linear alternatives when we compare point forecasts, with exactly opposite effect when we compare interval and density forecasts. In a recent paper, Siliverstors and van Dijk (2003) reiterate the above fact for G7 countries' monthly industrial production between 1960 and 2000. Medeiros et al. (2001) use Smooth Transitions and Neural Networks to test for and model nonlinearities in several monthly exchange rates time series and compare forecasting performance from these models with linear autoregressive and random walk models to conclude that non-linear models perform better than the linear ones. This follows a growing literature of modeling non-linearities in real 
exchange rate adjustment as either TAR or STAR processes, as described in Coakley and Fuertes (2001) and references within. Another macro variable, unemployment rate is also subjected to a lot of non-linear modeling investigation. For example, Montgomery et al. (1998) and Hansen (1997) fitted a threshold model to the US unemployment rate, Rothman (1998) and Parker and Rothman (1998) compare the performance of different non-linear models in forecasting the US unemployment rate. The mixed results either in support of linear or non-linear models point out some general facts regarding choice of inappropriate measures of forecast performance (see, Clements and Smith (1999)) and spurious non-linearity established by neglected heteroskedsticity, structural breaks or outliers. Employing Tsay's (1986) F-test to examine for non-linearity, we use two parametric nonlinear models as well as STAR and TAR to see if we can achieve forecast improvements vis-a-vis non-linear naive alternatives. These naive non-linear models are generated after either incorporating higher order polynomial terms of the lagged dependent variables or using the multiples of different dependent variables in the linear models as well as systems. Our analysis also points out that non-linear models are not necessarily better in terms of achieving better forecasts. In fact, it is the structural systems approach that is giving us the smaller prediction, thus supporting the underlying triangularity of this methodology as described earlier.

\section{Data and Descriptive Statistics}

There are three countries, Japan, USA, and UK in our study. For Japan, we have monthly data for import prices (IMP), producer prices (PPI), wholesale prices (WPI), trade-weighted exchange rates and short term interest rates from Bank of Japan's web site. There are seven industries in our analysis and the sample range is from $01 / 1971$ to $12 / 2002$ for a total of $n=384$ observations. The trade-weighted exchange rate is defined as the Japanese Yen vis-a-vis a weighted index of major trading countries' currencies. The civilian unemployment rate starts from 01/1976 and ends at $12 / 2002$ thus providing $n=324$ observations and we have collected this data from International Labor Organization's (ILO) web site. 
The dataset for USA consists of monthly observations for the SITC level import prices (IMP), producer prices (PPI), corresponding consumer price indices (CPI) and the trade-weighted exchange rate, defined as U.S. dollar/weighted average of 27 countries' currencies, as well as monthly observations for the overall civilian unemployment rate, federal funds rate and three-months Treasury bill rate. The sample range for data varies across industries. For example, the sample for monthly data for IMP runs from 01/1993 to 12/2002 for a total of $n=120$ observations for ten out of fourteen industries in our sample. For Mineral fuel and lubricants industries, we have $n=168$ observations, for the period from $01 / 1989$ to $12 / 2002$. And for the rest of the industries, we have $n=108$ observations obtained from $01 / 1994$ to $12 / 2002$. The data series were obtained from the Bureau of Labor Statistics's web site and from the Federal Reserve Bank of St. Louis's web site. Note that, the time interval choice is guided by monthly data availability of the import prices, as we use this in the analysis to look for the exchange rate pass-through effect.

For UK, the monthly data on import prices (IMP), producer prices (PPI) and civilian unemployment rate are collected from National Statistics Online. Monthly trade-weighted exchange rate and average discount rates for Treasury bills are downloaded from Bank of England's web site. In all of the data series, the sample time interval is from $01 / 1991$ to $12 / 2002$ for a total of $n=144$ observations. The data series and programs used for our analysis are available upon request.

All data series are transformed into a logarithmic scale and then differenced at lag one. Thereafter, all these series are taken as deviations from their sample means. For forecast evaluation, we set the validation sample of length $n_{1}=48$ for thirty-one industries across all the countries. The validation sample is of length $n_{1}=44$ for four industries in USA. However, the training sample, $n_{0}$, varies across countries as well as across industries, in case of USA. For example, the training sample is $n_{0}=336$ in Japan but $n_{0}=96$ in case of UK. Our choice of training and validation samples is such that, for the monthly data, we exclude 'outliers' from the validation samples; these observations are taken care by appropriate dummy variables during the training sample estimation.

Tables 1 to 4 (see Appendix 1) show descriptive statistics for all data series (logged, differenced 
and demeaned) in our sample, separated by respective countries. The tables report sample standard deviation, range, median, skewness and kurtosis and the normality test based on them. The first panel in each table depicts the statistics based on the entire sample while the second panel reports the statistics based on the validation sample only. In Japan (see Table 1), for full sample, the normality assumption is rejected for every industry, however, for the validation sample, this is accepted everywhere except for the chemical's industry (chemi). For USA (see Tables 2 and 3), three industrial PPIs for full sample and eight for the validation sample out of twelve different industries support normality. Regarding CPI, validation sample results show normality in every sampled cases, with only mineral fuel and lubricant's (mf) industry reporting non-normality for full sample analysis. Three industries in the full sample and seven industries in the validation sample support the normality assumption for UK industrial PPIs (see Table 4 for reference). Thus, in all the countries, we get considerable evidence of normality in the validation sample.

\section{Methodology}

\subsection{Linear Model Estimation}

For a generic time series $g_{t}$, we use $B^{j}$ to denote the backshift operator $B^{j} g_{t} \stackrel{\text { def }}{=} g_{t-j}, \nabla g_{t}$ to denote the first difference operator $\nabla g_{t} \stackrel{\text { def }}{=} g_{t}-g_{t-1}$. This will therefore denote growth rate. The univariate ARIMA models take the form:

$$
\phi(B) y_{t}=\boldsymbol{d}_{t}^{\top} \boldsymbol{\beta}+\sigma \xi_{t}
$$

where $y_{t}$ is $\nabla \log g_{t}$, and $\boldsymbol{d}_{t}$ is a $(k \times 1)$ vector of dummy variables and a constant term with associated coefficient vector $\boldsymbol{\beta}$. The autoregressive polynomial $\phi(B)$ is defined as $\phi(B) \stackrel{\text { def }}{=} 1-\sum_{i=1}^{m} \phi_{i} B^{i}$ and is usually restricted, with some of the $\phi_{i}$ 's being set to zero. It is also assumed that all the roots of $\phi(B)=0$ are outside the unit circle. The error series $\xi_{t}$ was white noise with unit variance for some of our models, $\xi_{t} \stackrel{\text { def }}{=} \epsilon_{t}$. Occasionally, however, it takes the form of a restricted moving average $\xi_{t} \stackrel{\text { def }}{=} \theta(B) \epsilon_{t}=\epsilon_{t}+\sum_{j=1}^{n} \theta_{j} \epsilon_{t-j}$, with some of the $\theta_{j}$ 's set to zero. The orders $(m, n)$ of the 
ARIMA models were chosen using standard techniques, that is the correlogram, overfitting tests and diagnostic tests on the estimated residuals. Conditional least squares were used for estimation, with backcasting employed only when the roots of the moving average polynomial $\theta(B)=0$ were outside the unit circle.

The model of equation (1) is appropriate for a linear time series. Therefore, we tested for linearity using the autoregressive part of the model and the omnibus F-type test of Tsay (1986), see also Fuller (1995) and Tsay $(2001)$. Let $\phi \stackrel{\text { def }}{=}\left(\phi_{1}, \ldots, \phi_{m}\right)^{\top}$ be the $(m \times 1)$ vector of autoregressive coefficients, $\boldsymbol{y}_{t-1} \stackrel{\text { def }}{=}\left(y_{t-1}, \ldots, y_{t-m}\right)^{\top}$ be the $(m \times 1)$ vector of lagged values and define the $m(m+$ 1) $/ 2 \times 1$ vector $\boldsymbol{h}_{t}$ that consists of all the squares and cross-products of the elements in $\boldsymbol{y}_{t-1}$. For example, if $m=2$ then $\boldsymbol{h}_{t}=\left(y_{t-1}^{2}, y_{t-2}^{2}, y_{t-1} y_{t-2}\right)^{\top}$. The test for linearity is the usual $F$-test for the null hypothesis $H_{0}: \delta=0$ in the augmented model:

$$
y_{t}=\boldsymbol{d}_{t}^{\top} \boldsymbol{\beta}+\boldsymbol{y}_{t-1}^{\top} \boldsymbol{\phi}+\boldsymbol{h}_{t}^{\top} \boldsymbol{\delta}+\sigma \xi_{t}
$$

where $\delta$ is the associated coefficient vector. The results from this test, performed over the entire sample, are given in tables 5,6 and 7 in the first appendix. The null hypothesis of linearity is rejected for six out of total thirty-five industrial price series in the sample. In case of USA, for mineral fuel and lubricants ( $\mathrm{mfl}$ ) industry, we get non-linearity and for UK, medicinal product (medi) series denotes absence of linearity. For Japan, four out of seven industrial WPIs show considerable non-linearity. The absence of normality and linearity from all of these series call for particular consideration in the modeling part and we comment on these issues in the following sections.

The simple system concept we have mentioned in the introduction part can be converted into an econometric framework, which can be used both for testing the implied triangularity of the threeequation system we propose and for estimating short and long-run effects on prices. As mentioned earlier, all our analysis is conducted in growth rates. Standard unit root and cointegration tests were performed for the levels, but we found no strong evidence of cointegration for almost all our systems. These tests are not presented here but are available on request. In what follows we 
describe the empirical implementation of a three equation system.

Consider a $(3 \times 1)$ vector with CPI inflation, PPI inflation and growth rate of import prices, say $\boldsymbol{z}_{t} \stackrel{\text { def }}{=}\left(y_{t}, x_{t 1}, x_{t 2}\right)^{\prime}$, and redefine the growth rate of the exchange rate as $x_{t 3} \equiv w_{t}$. All variables are taken as deviations from their respective sample means. We assume that $\boldsymbol{z}_{t}$ can be adequately modeled by a vector autoregression with an exogenous input variable (VARX) as:

$$
\boldsymbol{z}_{t} \stackrel{\text { def }}{=} \sum_{i=1}^{p} \boldsymbol{\Pi}_{i} \boldsymbol{z}_{t-i}+\sum_{j=1}^{q} \boldsymbol{\beta}_{j} w_{t-j}+\boldsymbol{u}_{t}
$$

where $\left\{\boldsymbol{\Pi}_{i}\right\}_{i=1}^{p}$ are $(3 \times 3)$ parameter matrices and $\{\boldsymbol{\beta}\}_{j=1}^{q}$ are $(3 \times 1)$ parameter vectors. The error vector $\boldsymbol{u}_{t}$ is assumed to be multivariate white noise with variance-covariance matrix $\boldsymbol{\Sigma}$. The model in the above equation will be our broadest, unrestricted model (U-model). The U-model was estimated using conditional least squares with the orders chosen by the Schwarz (BIC) criterion. The implied triangularity of the conceptual model is now testable using this model. Consider the restrictions implied by the following null hypothesis and corresponding to our first restricted model (R1-model):

$$
H_{0}:\left\{\pi_{a b}^{i}=0 \mid \text { for } a>b \text { and } a, b=1,2,3\right\} \quad \forall i
$$

where $\pi_{a b}^{i}$ is the $(a, b)$ coefficient of $\boldsymbol{\Pi}_{i}$. These restrictions imply absence of feedback from CPI inflation to PPI inflation and from CPI and PPI inflation to growth of import prices; they are immediately testable using a Wald-type test applied to the U-model.

If the above null hypothesis is rejected we proceed by eliminating the insignificant coefficients from the U-model and re-estimate the remaining parameters by seemingly unrelated regression (SUR). This is our second restricted model (R2-model), which we then compare to the U-model using a likelihood ratio (LR) test. If the R2-model is rejected in favor of the U-model we use the estimates from the U-model to compute the long-run effects; if the R2-model is not rejected we use its estimates to compute the long-run effects. Similarly, if the null hypothesis of triangularity is not rejected, we proceed by eliminating the insignificant coefficients from the R1-model and re-estimate the remaining parameters using SUR. This is our third restricted model (R3-model), which we now 
compare to the R1-model using a LR test. Depending on whether the R3-model is rejected or not we use the estimates from either the R1-model or the R3-model to calculate the long-run effects. We are reporting the model choice results in the second appendix. Forecasts coming from these reduced models are denoted by SYS in the first appendix.

To illustrate the computation of the long-run effects, consider the U-model and re-write it using lag operator notation as:

$$
\boldsymbol{\Pi}(L) \boldsymbol{z}_{t}=\boldsymbol{\beta}(L) w_{t}+\boldsymbol{u}_{t}
$$

where $\boldsymbol{\Pi}(L) \stackrel{\text { def }}{=} \boldsymbol{I}_{3}-\sum_{i=1}^{p} \boldsymbol{\Pi}_{i} L^{i}$ and $\boldsymbol{\beta}(L) \stackrel{\text { def }}{=} \sum_{j=1}^{q} \boldsymbol{\beta}_{j} L^{j}$. When the system is in long-run equilibrium we expect that the variables do not deviate substantially from some fixed values, say their respective means $\boldsymbol{z}^{*} \stackrel{\text { def }}{=} \mathrm{E}\left[\boldsymbol{z}_{t}\right], w^{*} \stackrel{\text { def }}{=} \mathrm{E}\left[w_{t}\right]$ and $\boldsymbol{u}^{*} \stackrel{\text { def }}{=} \mathrm{E}\left[\boldsymbol{u}_{t}\right]=0$. Therefore, we have the representation:

$$
\Pi(1) \boldsymbol{z}^{*}=\boldsymbol{\beta}(1) w^{*}
$$

from which all long-run effects can be easily computed by summing the estimates of the $\boldsymbol{\Pi}_{i}$ 's and the $\boldsymbol{\beta}_{i}$ 's. For example, the long-run effects of the exchange rate growth on CPI inflation, PPI inflation and growth of import prices are given by the estimate of the vector $\partial \boldsymbol{z}^{*} / \partial w^{*} \stackrel{\text { def }}{=}[\boldsymbol{\Pi}(1)]^{-1} \boldsymbol{\beta}(1)$.

Letting $\boldsymbol{o}_{t} \stackrel{\text { def }}{=}\left(y_{t}, x_{t 1}, x_{t 2}, x_{t 3}, r_{t}, u n_{t}\right)^{\top}$ be a $(6 \times 1)$ vector, we can write the unrestricted VAR1 model as:

$$
\boldsymbol{\Phi}(B) \boldsymbol{o}_{t}=\boldsymbol{C} \boldsymbol{d}_{t}+\boldsymbol{S} \boldsymbol{\epsilon}_{t}
$$

where the matrix autoregressive polynomial $\boldsymbol{\Phi}(B)$ is defined as $\boldsymbol{\Phi}(B) \stackrel{\text { def }}{=} \boldsymbol{I}-\sum_{i=1}^{p} \boldsymbol{\Phi}_{i} B^{i}$ and we assume that obeys the stability condition $\operatorname{det}\{\boldsymbol{\Phi}(1)\} \neq 0 . r_{t}$ and $u n_{t}$ denote changes in interest rate and unemployment rate, respectively. As before, $\boldsymbol{d}_{t}$ is a vector of dummy variables and constant term with associated coefficient matrix $\boldsymbol{C}$, while $\boldsymbol{\epsilon}_{t}$ is bivariate white noise with identity covariance matrix and $\boldsymbol{S}$ is the lower triangular decomposition for the covariance matrix $\boldsymbol{\Sigma} \stackrel{\text { def }}{=} \boldsymbol{S} \boldsymbol{S}^{\top}$. SUR method of estimation is used in estimating the model's parameters with the autoregressive order set as like the VARX model. After this initial estimation, we drop all the import prices and exchange 
rate variables from the above model and get VAR2, which represents that $\boldsymbol{o}_{t}$ is a $(4 \times 1)$ vector now. We again estimate this VAR2 using SUR. The results from SUR estimation are those reported in the first appendix.

\subsection{Non-linear Model Estimation}

Out of thirty-five price series in the analysis, we found non-linearity for six different price series across three countries. We fit four different models to explain non-linearity and try to see if the forecast performance improves once we employ these non-linear models.

The first model we consider is nothing but the model shown in equation 11. After rejecting the null of linearity, we estimate this model with non-linear terms, identified by vector $\boldsymbol{h}_{t}$ that consists of all the squares and cross-products of the elements in $\boldsymbol{y}_{t-1}$. We use conditional least squares to estimate this model and then we perform three step ahead out-of-sample forecasts. RMSEs coming from these are reported in the tables as N1, called so as we term this model as the first naive non-linear model.

The second naive non-linear model (RMSEs denoted by N2 in the tables) is built from the systems, when we incorporate these non-linear terms from equation 11 into the systems given by equations 12 and 13. We use SUR to estimate these non-linear systems and then generated out-ofsample forecasts. This is again a naive approach as we are not estimating a multivariate non-linear system in full.

The third model we estimate is a pure non-linear parametric model, as described in Terasvirta (1994). We take a Logistic Smooth Transition Autoregressive (LSTAR) model of order $p$ as:

$$
y_{t}=\boldsymbol{\pi}_{10}+\boldsymbol{\pi}_{1}^{\top} \boldsymbol{w}_{t}+\left(\boldsymbol{\pi}_{20}+\boldsymbol{\pi}_{2}^{\top} \boldsymbol{w}_{t}\right)\left(1+\exp \left[-\gamma\left(y_{t-d}-c\right)\right]\right)^{-1}+u_{t}
$$

where

$$
u_{t} \sim \operatorname{nid}\left(0, \sigma_{u}{ }^{2}\right), \boldsymbol{\pi}_{j}=\left(\pi_{j 1}, \pi_{j 2}, \ldots, \pi_{j p}\right)^{\top} \text { forj }=1,2, \gamma>0 \text { and } \boldsymbol{w}_{t}=\left(y_{t-1}, y_{t-2}, \ldots, y_{t-p}\right)^{\top}
$$

$\gamma$ in the above equation denotes smoothness parameter or transition rate, $c$ is the threshold value 
which represents the change from one regime to another, and $d$ is the number of lags of transition variable. We use AIC criterion to select a proper subset of lags accompanied by portmanteau tests for residual autocorrelation. In most of the cases, we ended up using the same lags as in the linear ARIMA model described earlier. To select the delay parameter, we deviate from the usual method of employing linearity test vis-a-vis the non-linear alternative. Terasvirta (1998), Perez-Rodriguez (2000), among others provide detailed references on this method. Instead, we estimate the model with a number of different delay values and then select the one that gives us the best prediction. Conditional least square estimation is used to estimate the parameters of the model, and then we have done three step ahead out-of-sample forecasts from this model. Results of the RMSE values from the model is tabulated as STAR in the appendix.

Our last non-linear model is an one-regime Threshold Autoregression Model (TAR), as proposed by Tong (1990) and Tong and Lim (1980). In this paper, we follow the Band-TAR specification adopted by Coakley and Fuertes (2001):

$$
y_{t}=A(t)^{L} I_{t}\left(z_{t-d}<-\theta\right)+B(t) I_{t}\left(-\theta \leq z_{t-d} \leq \theta\right)+A(t)^{U} I_{t}\left(z_{t-d}>\theta\right)+e_{t}
$$

where

$$
\begin{gathered}
A(t)^{L}=\alpha_{1}\left(z_{t-1}+\theta\right)+\ldots .+\alpha_{p}\left(z_{t-p}+\theta\right) \\
A(t)^{U}=\alpha_{1}\left(z_{t-1}-\theta\right)+\ldots .+\alpha_{p}\left(z_{t-p}-\theta\right) \\
B(t)=\beta_{0}+\beta_{1} z_{t-1}+\ldots .+\beta_{q} z_{t-q}
\end{gathered}
$$

where the superscripts $U$ and $L$ refer to the upper and lower bands, respectively. $I_{t}$ represents a Heaviside indicator function, which equals 1 when the relevant condition is fulfilled and 0 otherwise, $\theta$ is the threshold value, $d$ is the delay parameter, and $e_{t}$ is an i.i.d $N\left(0, \sigma^{2}\right)$ noise term. The process $y_{t}$ is guided by an inner $\left(\beta_{j}\right)$ or outer $\left(\alpha_{i}\right)$ autoregression on the basis of it's own lagged value, $y_{t-d}$, which acts as the threshold or switching variable. If the roots of the outer band characteristic 
equation lie inside the unit circle then, for $\left|y_{t-d}\right|>\theta$, the process reverts toward the band $[-\theta, \theta]$ and is stationary overall. Conditional least square estimation method is used to get the parameter values with the best-fit model is selected by BIC criterion. After estimation, we look for one-step ahead forecasting from this model, RMSEs of those are reported as TARs in the appendix tables.

We evaluated the forecasting performance of all the above models (except TAR model) using one, two, and three-steps ahead, rolling origin forecasts. In this case, the sample is training sample is a moving window of fixed width $n_{0}$, and the coefficients are updated as the window 'rolls' over all the observations in the validation sample. We expect that in this way we will obtain a more accurate treatment of the forecasting performance of different models. Letting $\widehat{y}_{t+h}$ denote the $h$ step ahead forecast made at forecast origin $t$ we compare models based on their root mean-squared error (RMSE):

$$
\mathcal{R}_{M S E}=\left[\frac{1}{n-n_{0}} \sum_{t=n_{0}+1}^{n}\left(y_{t}-\widehat{y}_{t+h}\right)^{2}\right]^{1 / 2}
$$

which is equal to the forecast error standard deviation over the validation sample. A lower $\mathcal{R}_{M S E}$ indicates better model performance.

\section{$5 \quad$ Linear Models and Forecasting Performance}

The out-of-sample forecast performances from four different models are presented in the first appendix. Here, columns of the tables report RMSEs from the univariate ARIMA model (ARMA), system (SYS), VAR1 model (VAR1) and VAR2 model (VAR2) respectively. For all industries across all countries, short-run forecasts (denoted by one month ahead forecasts) show that the SYS outperforms other models as well as ARMA models in fifty-five percent cases. Similarly, for the long-run forecasts (i.e., for two and three months ahead predictions), SYS is the best predictor in fifty-eight percent of the sampled cases. Overall, for all the horizons, the proposed pass-through effect improves the forecast prediction in forty-three percent of sampled industries prices. Looking at the industry-level prices for all three countries, SYS for chemical industry in all countries 
short-run forecasts come out as the superior predictor. However, ARMA for metal industry in the short-run is the efficient predictor, thus showing no as such short-run pass-through effect. SYS for textiles and wood in Japan and UK in the long-run show the least RMSEs, and, therefore, termed as the best forecast model as compared to the other alternatives. Also petrol and fuel industry SYS results point that in the long-run, the forecasts coming out from this model incorporating pass-through is the efficient one as it outperforms all the other models with the least RMSE. These results support one of the general observations that because of its importance in every country's imported goods bundle, price for petrol and fuel are more susceptible to changes in the exchange rate and so the changes in pass-through effect follows. In the following subsections, we discuss industry-level forecast performance for the three countries in the sample.

\subsection{Evidence from industry-level WPIs in Japan}

Table 8 reports the rolling forecast performance of wholesale prices across all the seven industries in Japan. WPI forecasts coming from the system after incorporating the exchange rate pass-through effects provide the best evidence of accuracy for two-months ahead horizon, as the results show the lowest RMSEs for almost eighty-six percent of the sampled industries. Within these industries, chemical (chemi) provides the highest improvement and petrol and fuel (petrol) reports the lowest improvement from system forecasts. The predictions signify that exchange rate pass-through effect can be one potential source to achieve better forecasts in future. However, for the other two months ahead predictions, the system produces better forecasts for three out of seven industries in the sample, showing that pass-through effects may not have enough explanatory power for the remaining four industries' out-of-sample price predictions. Metal (metal) and petrol industry prices show the highest extent of forecast accuracy increase for one-month and two-months ahead prediction horizons respectively. Two-month and three-month ahead forecasts for metal depict superiority of the univariate model in the longer horizon but for petrol and fuel, the systems forecasts fare better. The traditional forecasting model (i.e., VAR2), based on interest rate and unemployment rate, always outperforms the system over all horizons for food industry (food) 
prices. VAR2 also performs better than the system in two other instances, for one-month ahead petrol and wood industry (wood) forecasts. The results show that in short run, there may not be satisfactory pass-through of exchange rates that can explain the variability in these industries' domestic prices. Rather, domestic factors have more explanatory powers at least for these industries in the short run. For textiles (textiles), wood and petrol industries', consistent forecast accuracy is reported from the system for more than one month ahead forecast horizons, pointing out the fact that exchange rate pass-through effect has significant long run impact for these three industries. Evidence from chemical industry also shows the relevance of pass-through effect in one-month and two-months ahead forecasts. As a result, the conjecture of achieving forecast accuracy remain valid in almost fifty-eight percent of the reported cases. Two representative manufacturing industries in our sample, machinery and equipment (mach) and metal, however, contradict this view, as we get the performance from univariate ARMA models are better for two out of three forecast horizons. A quick look at the linearity tests table (see Table 4 for reference) shows non-linear price movements for the machinery and equipment industry, and therefore, the forecasting performance based on a linear system may not be adequate to capture this fact. This argument, on the other hand, is void in cases of petrol, textiles and wood industries', as there is significant forecast error reduction with lowest RMSEs from systems in the longer forecasting horizons, albeit non-linearity in these industries data series. The later evidence supports the modeling technique involving pass-through, as it provides superior forecasts.

\subsection{Evidence from Industry-Level PPIs and CPIs in USA}

Monthly rolling predictions for PPIs in USA (see Table 9) support the contention of achieving better forecasts, as more than fifty-percent of the systems results provide lower RMSEs compared to other models for all three forecast horizons. The sectoral evidences point out the significance of exchange rate pass-through effects for predicting domestic producer prices in future. Chemical's (chemi) and

inorganic chemical's (inor-che) industries provide mixed support for forecast improvement from the systems, as for three-months horizons predictions, VAR2 model performs better than the system, 
though the system predicts more accurate prices in shorter horizons. As a result, at least sixty-two percent of the industries provide evidence of pass-through at various forecast horizons. Eight out of total twelve industries show that there is forecast improvement from the system considering the one-month ahead rolling forecasts with organic chemical's (org-che) industry showing the highest and furniture's (furni) industry showing the least improvements over all the models. These two industries remain the highest and lowest improvement generator for two-months ahead forecasts also with the system forecasts for seven industries now outperforming all the other model forecasts. The chemical industry drops out from the category of least one-month ahead systems forecasts now. Three-months ahead forecasts show the same result as the two-months ahead case, with fifty-percent of the industries now supporting the system. Organic chemical's, again, provides the highest forecast difference in comparison with all other industries with furniture, beverages (beve) and rubber (rubber) now showing only marginal improvement. Therefore, for all the horizons, organic chemical industry achieves the best forecast improvement and furniture the least forecast improvement, thus pointing out that the extent of pass-through effect is much larger in the former and comparatively lower in the later industry. Metalliferous ores ((metal), which is part of broad SITC category, Crude materials except fuel) and fruit ((fruit), which is a sub category of SITC Food and Live animals' industry) industrial prices, however, show that there is no as such passthrough effect in these sectoral producer prices and rely on the univariate model to produce forecast improvement. We have two sub categories, rubber and non-metallic minerals manufactures (nmmin) of the broad Manufactured goods industry, and forecasting results from these can also be termed as mixed in terms of achieving system forecast accuracy. For example, evidence from rubber prices show the lowest RMSEs in two-months and three-months forecasts from the system, but in comparison with the other industry, there is no evidence of forecast accuracy in terms of the systems. We mention this result in particular, as Engel (1999) also points that there is not much evidence of exchange rate pass-through towards the US Manufacturing industry in the short run, and our forecast results partially confirm that. For all industries in USA, after incorporating standard control variables for inflation, interest rates and unemployment rates, the forecast performances 
are better than the VAR1 model, which takes of all potential pass-through effects as well as these controls.

For CPI forecasting (see Table 10), mixed results are obtained from the system. For mineral fuel industry (mfl), the system performs best over all forecast horizons. Food and beverages (food.) industry and apparels (appa.) industries, on the other hand, support univariate ARIMA model and VAR2 model respectively. Therefore, exchange rate pass-through is not uniform across sectors and for some cases, it is true that domestic unemployment rate and interest rate dynamics can predict the consumer prices much accurately. Apparels industry case can be termed as a support towards earlier finding by Tootell (1998), which suggests that domestic variables are sufficient to explain past US inflation.

\subsection{Evidence from Industry-Level PPIs in UK}

Comparison from one-month ahead forecasts (see Table 11) for UK industrial prices show that for seven out of total thirteen categories in our sample, there is significant improvement from the system predictions as compared to other models. Wood industry (wood), which is a part of Crude materials category under SITC depicts the least and pulp (pulp), also belonging to the same broad SITC classification reports the highest improvement in out-of-sample forecasts, pointing out the fact that there is considerable heterogeneity even within the same broad industrial structure. As a result, we have to be careful in predicting real world prices of UK Crudes, as the pass-through effects generate considerable forecast variation across the sub categories of this industry. From the two-months and three-months ahead predictions, there is overwhelming support for the system forecasting accuracy with seventy-seven percent of the sampled industries reporting the least RMSEs from the systems as compared to other models in the analysis. As before, pulp and wood remain the best and least prediction enhancement categories respectively, with textile fabrics (tex-fabs), nonferrous metals (nonfme) and electrical machinery (el-mach) industries joining the least forecast error prediction category from the systems with higher forecast horizons. Metal ores (metal) and medicinal products (medi) prices for all forecast horizons report lowest RMSEs from the univariate 
models thus depicting no possible improvements from exchange rate pass-through effects. Another reason for this may be linearity assumption in the models, whereas the data series is not linear, as is evident for the medicinal products industry (see Table 6 for reference). The VAR2 model, with interest rates and unemployment rates as standard control variables for inflation prediction outperforms the system prediction only for the plastics industry (plastics), showing ineffectiveness of the possible exchange rate pass-through effects to predict PPI. Overall, fifty-four percent of the forecast results for UK point out some kind of exchange rate pass-through effects to producer prices that leads to forecast accuracy over all forecast horizons, after incorporating this effect in the system.

\subsection{Evidence from Industry-specific prices across countries}

Our system concept and forecast performance improvement is supported by cross-country evidences also. For chemical's, the system results outperform all other models over all forecast horizons in UK, for one-month and two-months ahead forecasts in Japan and for one-month ahead predictions in USA. So, in the short-term forecasts, there is significant exchange rate pass-through effects that explain lower inflation in chemical's production prices in these countries. Results for longer horizon, however, show that domestic factors provide better explanation for future forecasts in USA and past values of this industry's prices predict future prices more accurately in Japan.

Organic chemical, a sub category of Chemical's industry also support forecast accuracy from the systems in USA and UK. Results from Machinery, too, point out that there is significant forecast improvement relying on the systems approach. Two-months ahead price predictions in Japan, all horizon forecasts from UK and results from electrical machinery, which is a part of broad Machinery category in USA provide ample support for exchange rate pass-through. Long term forecasts of petrol in Japan and USA serve another pointer for the role played by pass-through effect in future gasoline price determination. All forecast horizon results in Japan and one-month and threemonths ahead forecast error reduction in UK for textile's industry also provide substantial evidence towards the systems concept proposed to achieve better forecasts. In case of USA, however, VAR2 
model outperforms all other models in textile industry price prediction, pointing that, standard control variables may have better explanatory power. For wood industry, Japan's all future horizon forecasts and UK's one-month and three-month ahead results prove the supremacy of the systems concept to achieve better predictions. Only in metal and food industries, forecasts from systems are not the best as these do not provide the least prediction errors. All evidences therefore point out that for future price prediction in a number of important industries across these advanced countries, exchange rate pass-through effect can be judged as an important determinant of long term effects and we can have forecast accuracy if we take into account this effect.

\section{Forecasting Performance from Non-linear Prices across Coun- tries}

Tables 12 and 13 in the first appendix show the results from four alternative non-linear models analyzed here after finding non-linearity in the corresponding prices across countries. Table 12 denotes RMSEs for Japanese WPIs and Table 13 has the result for UK. First two columns for each-month ahead forecasts in the tables report RMSEs from the naive nonlinear models. STAR denotes RMSEs generated from out-of-sample forecasting after using Logistic Smooth Transition Autoregressive (STAR) models for the corresponding non-linear price series. The last column depicts RMSEs from out-of-sample forecasting generated after employing one-regime Threshold Autoregressive (TAR) models for these non-linear price series. As a result, last two columns depict actual non-linear model forecasts vis-a-vis "naive" forecasts from simple alternative non-linear models.

If the price series follow considerable non-linear dynamics, then forecasting performance from actual non-linear models will show considerable improvement over naive non-linear or linear models. However, for Japan, Petrol, Textiles and Wood WPIs show that naive non-linear forecasts from the systems performs the best, both in the short-run and long-run ahead cases. For Mach WPI, in the long-run, the naive non-linear ARMA performs the best, with the short-run result again supporting 
the systems approach. As a result, we can say that these price series data generating process is not guided by any parametric non-linear procedure. It's rather guided by some structural adjustments in the economy, which is being explained by the exchange rate pass-through effect, as described in the systems approach.

Results from Medi. PPI for UK, on the other hand, support considerable non-linearity as the RMSEs from the parametric LSTAR model report the lowest RMSEs. This disproves the claim that exchange rate pass-through effect may have some explanatory power for future price movements. This is also supported from table 11, as the univariate ARMA models depict the lowest RMSEs. A quick look at table 13 shows marginal improvements in terms of short-run and long-run effects, but nevertheless, it drives the point that there is considerable non-linearity in Medi. pricing which may be totally disconnected with the exchange rate fluctuations. This may support the point that there is some amount of local currency pricing or pricing to market going on for future price determination in this industry.

\section{Concluding remarks}

We evaluate the forecasting performance of a number of models for domestic inflation for three developed countries, Japan, USA and UK. Our results are part of a project dealing with the construction and evaluation of forecasting models that can be of practical use in real-time forecasting. Our analysis, based on linear models as well as non-linear models, suggests that models based on exchange rate pass-through effects improve upon the forecasts of three other linear models in a majority of cases. This, therefore, support the contention that, "special factors", i.e., import prices and exchange rate can provide significant policy guidance for domestic monetary authorities. With the advanced countries in our analysis supporting flexible exchange rate regime with higher level of capital mobility, targeting and achieving better inflation forecasts provide an important guidance to other countries domestic monetary policy choice. Among the data used in the paper, six industrial price series failed to pass the linearity test and we also explored the potential advantages of nonlin- 
ear models in forecasting future prices. Considering non-linearity, the results are mixed, as naive non-linear models perform better than the parametric and non-parametric non-linear alternatives in half of the cases. For future analysis, we are exploring multivariate non-linear models to capture the true non-structural data generating process of these price series vis-a-vis structural models. 


\section{References}

1. Bhattacharya, P. S., C. Karayalcin and D. Thomakos, "Exchange Rate Pass-Through and Relative Prices: An Industry-Level Empirical Investigation", November, 2003. Working paper, Florida International University, Miami, FL 33199.

2. Boldin, Michael D., "A New Era for Inflation or Will Inflation Pick Up Before This Expansion Ends?", 1998. Unpublished paper, Conference Board.

3. Coakley, J. and A. Fuertes, 2001. "Border Costs and Real Exchange Rate Dynamics in Europe", Journal of Policy Modeling, vol. 23, pp. 669-676.

4. Clements, M. P. and J. Smith, 1999. "A Monte Carlo Study of the Forecasting Performance of Empirical SETAR Models", Journal of Applied Econometrics, vol. 14, pp. 123-141.

5. Franses, P. H. and D. v. Dijk, 2000. Non-linear Time Series Models in Empirical Finance, Cambridge University Press, Cambridge, U.K.

6. Franses, P. H. and D. v. Dijk, "The Forecasting Performance of Various Models for Seasonality and Non-linearity for Quarterly Industrial Production” Econometric Institute Report EI 200114, No. 14, April, 2001.

7. Granger, C. W. J. and T. Terasvirta, 1993. Modeling Nonlinear Economic Relationships, Oxford University Press, Oxford, U.K.

8. Hamilton, J. D., 1989. "A New Approach to the Economic Analysis of Nonstationary Time Series subject to Changes in Regime", Econometrica, vol. 57, pp. 357-384.

9. Hansen B. E., 1997. "Inference in TAR Models", Studies in Nonlinear Dynamics and Econometrics, vol. 2, pp. 1-14.

10. Devereux, Michael B., 1997. "Real Exchange Rates and Macroeconomics: Evidence and Theory", Canadian Journal of Economics, vol. 30, pp. 773-808. 
11. Engel, Charles, "The Responsiveness of Consumer Prices to Exchange Rates and The Implication for Exchange-Rate Policy: A Survey of A Few Recent New Open-Economy Macro Models", Working Paper of The National Bureau of Economic Research, No. 8725, January, 2002.

12. Engel, Charles, 1999. "Accounting for Real Exchange Rate Changes", Journal of Political Economy, vol. 107, pp. 507-538.

13. Franses, P. H. and M. Ooms, 1997. "A Periodic Long-Memory Model for Quarterly UK Inflation", International Journal of Forecasting, vol. 13, pp. 117-126.

14. Fildes, R. and H. Stekler, 2002. "The State of Macroeconomic Forecasting", Journal of Macroeconomics, vol. 24, pp. 435-468.

15. Fuller, W.A., 1996. Introduction to Statistical Time Series, 2nd. edition, John Wiley, New York.

16. Kim, K., 1998. "US Inflation and the Dollar Exchange Rate: A Vector Error Correction Model', Applied Economics, vol. 30, pp. 613-619.

17. Koenig, Evan F., "What's New About the New Economy? Some Lessons from the Current Expansion", Southern Economy, Federal Reserve Bank of Dallas, July/August, 1998, pp. $7-11$.

18. Krugman, Paul K., 1987. "Pricing to Market When the Exchange Rate Changes", in Real Financial Linkages Among Open Economies, ed. by Sven W. Arndt and J. David Richardson., MIT Press, Cambridge, Massachusetts.

19. Lane, Philip R., 2001. "The New Open Economy Macroeconomics: A Survey", Journal of International Economics, vol. 54, pp. 235-266.

20. McCarthy, Jonathan, "Pass-Through of Exchange Rates and Import Prices to Domestic Inflation in Some Industrialized Economies", Staff Reports of Federal Reserve Bank of New York, 
No. 111, September, 2000.

21. Medeiros, M. C., A. Veiga and C. E. Pedreira, "Modeling Exchange Rates: Smooth Transitions, Neural Networks, and Linear Models", IEEE Transactions on Neural Networks, Special Issue on Financial Engineering, forthcoming.

22. Mills, T. C. and G. Pepper, 1999. "Assessing the Forecasters", International Journal of Forecasting, vol. 15, pp. 247-257.

23. Montgomery A. L., V. Zarnowitz, R. Tsay and C. Tiao, 1998. "Forecasting the U.S. Unemployment Rate", Journal of the American Statistical Association, vol. 93, pp. 478-493.

24. Moosa, Imad, 1998. "Are Commodity Prices a Leading Indicator of Inflation?", Journal of Policy Modeling, vol. 20, pp. 201-212.

25. Obstfeld, Maurice, 2001. "International Macroeconomics: Beyond the Mundell-Fleming Model", IMF Staff Papers: Special Issue, vol. 47, pp. 1-39.

26. Obstfeld, Maurice, "Exchange Rates and Adjustment: Perspectives from the New Open Economy Macroeconomics", mimeo, July, 2002.

27. Parker, R. E. and P. Rothman, 1998. "The Current Depth-of-recession and Unemployment Rate Forecast", Studies in Nonlinear Dynamics and Econometrics, vol. 2, pp. 151-158.

28. Pecchenino, R. A., 1992. "Commodity Prices and the CPI: Cointegration, Information and Signal Extraction", International Journal of Forecasting, vol. 7, pp. 493-500.

29. Rothman, P., 1998. "Forecasting Asymmetric Unemployment Rates", Review of Economics and Statistics, vol. 80, pp. 164-168.

30. Siliverstovs, B. and D. v. Dijk, "Forecasting Industrial Production with Linear, Nonlinear and Structural Change Models" Econometric Institute Report EI 2003-16, No. 16, May, 2003. 
31. Stock, J. H. and M. Watson, 1999. "Forecasting Inflation", Journal of Monetary Economics, vol. 44, pp. 293-335.

32. Terasvirta, Timo., 1994. "Specification, Estimation, and Evaluation of Smooth Transition Autoregressive Models", Journal of the American Statistical Association, vol. 89, pp. 208218.

33. Tong, H., 1990. Non-linear Time Series: A Dynamical System Approach, Oxford University Press, Oxford, U.K.

34. Tootell, Geoffrey M. B., 1998. "Globalization and U.S. Inflation", New England Economic Review, July/August, pp. 21-33.

35. R. S. Tsay, 1986. "Non-linearity tests for time series", Biometrika, 73, pp. 461-466.

36. Tsay, R.S., 2001. Analysis of Financial Time Series, John Wiley, New York.

37. Zarnowitz, V. and P. Braun, "Twenty two years of the NBER-ASA Quarterly Outlook Surveys: Aspects and Comparisons of Forecasting Performance", Working Paper of The National Bureau of Economic Research, No. 3965, January, 1992.

38. Zellner, A. and B. Chen, 2001. "Bayesian Modeling of Economies and Data Requirements", Macroeconomic Dynamics, forthcoming. 


\section{Appendix 1: Tables}

Table 1. Descriptive Statistics for WPIs in Japan

\begin{tabular}{c|cccccc|}
\cline { 2 - 7 } Industry & $s$ & $R$ & $m$ & $\mathcal{S}$ & $\mathcal{K}$ & $\mathcal{N}$ \\
\cline { 2 - 7 } & \multicolumn{5}{|c|}{ Full Sample } \\
\cline { 2 - 7 } Chemi & 0.011 & 0.163 & -0.001 & 5.743 & 60.971 & 55591.070 \\
Food & 0.006 & 0.0053 & -0.001 & 2.000 & 10.690 & 1195.864 \\
Mach & 0.006 & 0.069 & 0.001 & 2.312 & 18.901 & 4364.384 \\
Metal & 0.008 & 0.136 & -0.002 & 7.706 & 91.737 & 129112.300 \\
Petrol & 0.025 & 0.286 & -0.003 & 1.747 & 14.835 & 2423.691 \\
Textiles & 0.011 & 0.141 & -0.001 & 3.418 & 30.628 & 12893.400 \\
Wood & 0.024 & 0.344 & -0.003 & 4.794 & 47.554 & 33059.400 \\
\cline { 2 - 7 } & & & Validation Sample & \\
\cline { 2 - 7 } Chemi & 0.005 & 0.028 & -0.001 & 0.636 & 4.242 & 6.193 \\
Food & 0.003 & 0.013 & -0.002 & 0.015 & 2.821 & 0.064 \\
Mach & 0.005 & 0.019 & -0.001 & 0.051 & 2.324 & 0.913 \\
Metal & 0.002 & 0.009 & -0.002 & -0.479 & 3.610 & 2.533 \\
Petrol & 0.018 & 0.085 & 0.003 & -0.057 & 2.817 & 0.091 \\
Textiles & 0.006 & 0.024 & -0.001 & 0.402 & 2.327 & 2.155 \\
Wood & 0.006 & 0.029 & -0.003 & -0.096 & 2.774 & 0.174 \\
\cline { 2 - 6 } & & & & & & \\
\hline
\end{tabular}


Table 2. Descriptive Statistics for PPIs in USA

\begin{tabular}{|c|c|c|c|c|c|c|}
\hline \multirow[t]{2}{*}{ Industry } & $s$ & $R$ & $m$ & $\mathcal{S}$ & $\mathcal{K}$ & $\mathcal{N}$ \\
\hline & \multicolumn{6}{|c|}{ Full Sample } \\
\hline Meat & 0.014 & 0.072 & -0.001 & 0.049 & 2.549 & 1.054 \\
\hline Fruit & 0.002 & 0.012 & -0.001 & 0.583 & 3.260 & 7.083 \\
\hline Beve & 0.003 & 0.024 & -0.001 & 0.964 & 5.210 & 42.679 \\
\hline Metal & 0.005 & 0.033 & -0.001 & 0.077 & 4.875 & 26.366 \\
\hline Chemi & 0.005 & 0.029 & -0.001 & 0.406 & 3.366 & 3.938 \\
\hline Org-che & 0.015 & 0.101 & -0.001 & 0.769 & 5.950 & 49.367 \\
\hline Inor-che & 0.010 & 0.070 & -0.001 & 2.216 & 11.840 & 484.961 \\
\hline Rubber & 0.003 & 0.017 & -0.001 & 0.950 & 4.530 & 29.538 \\
\hline Nm-min & 0.002 & 0.012 & -0.001 & 0.555 & 3.735 & 8.794 \\
\hline Me-mach & 0.004 & 0.033 & -0.001 & 0.744 & 5.030 & 31.440 \\
\hline El-mach & 0.001 & 0.011 & 0.001 & -0.371 & 3.647 & 4.801 \\
\hline \multirow[t]{2}{*}{ Furni } & 0.001 & 0.156 & -0.001 & -0.449 & 4.733 & 26.552 \\
\hline & \multicolumn{6}{|c|}{ Validation Sample } \\
\hline Meat & 0.014 & 0.072 & -0.001 & 0.058 & 2.950 & 0.032 \\
\hline Fruit & 0.001 & 0.001 & -0.001 & 0.751 & 3.612 & 5.265 \\
\hline Beve & 0.004 & 0.017 & -0.001 & 1.419 & 5.214 & 25.936 \\
\hline Metal & 0.004 & 0.016 & -0.001 & -0.154 & 2.475 & 0.740 \\
\hline Chemi & 0.006 & 0.027 & -0.001 & -0.281 & 2.759 & 0.750 \\
\hline Org-che & 0.016 & 0.060 & 0.004 & -0.614 & 2.576 & 3.096 \\
\hline Inor-che & 0.011 & 0.070 & -0.001 & 2.992 & 17.158 & 472.597 \\
\hline Rubber & 0.003 & 0.017 & 0.001 & 0.668 & 4.431 & 7.674 \\
\hline Nm-min & 0.002 & 0.010 & -0.001 & 0.111 & 2.708 & 0.270 \\
\hline Me-mach & 0.001 & 0.011 & -0.001 & -1.107 & 8.903 & 72.875 \\
\hline El-mach & 0.002 & 0.011 & -0.001 & -0.611 & 2.660 & 3.217 \\
\hline Furni & 0.001 & 0.001 & -0.001 & -0.517 & 4.083 & 4.117 \\
\hline
\end{tabular}


Table 3. Descriptive Statistics for CPIs in USA

\begin{tabular}{c|cccccc|}
\cline { 2 - 7 } Industry & $s$ & $R$ & $m$ & $\mathcal{S}$ & $\mathcal{K}$ & $\mathcal{N}$ \\
\cline { 2 - 7 } & \multicolumn{5}{c|}{ Full Sample } \\
Mfl & 0.038 & 0.262 & -0.005 & 0.410 & 5.936 & 31.232 \\
Food. & 0.003 & 0.026 & -0.001 & 1.875 & 13.510 & 5.660 \\
Appa. & 0.020 & 0.075 & -0.001 & 0.027 & 1.855 & 5.854 \\
\cline { 2 - 7 } & \multicolumn{5}{c}{ Validation Sample } \\
Mfl & 0.054 & 0.262 & -0.001 & 0.053 & 3.497 & 0.435 \\
Food. & 0.001 & 0.009 & -0.001 & 0.772 & 3.503 & 1.843 \\
Appa. & 0.023 & 0.075 & -0.006 & 0.214 & 1.660 & 3.622 \\
\cline { 2 - 7 } & & & &
\end{tabular}


Table 4. Descriptive Statistics for PPIs in UK

\begin{tabular}{|c|c|c|c|c|c|c|}
\hline \multirow[t]{2}{*}{ Industry } & $s$ & $R$ & $m$ & $\mathcal{S}$ & $\mathcal{K}$ & $\mathcal{N}$ \\
\hline & \multicolumn{6}{|c|}{ Full Sample } \\
\hline Toba & 0.019 & 0.160 & -0.005 & 2.176 & 12.152 & 611.889 \\
\hline Pulp & 0.040 & 0.309 & -0.001 & -1.286 & 8.589 & 225.594 \\
\hline Wood & 0.010 & 0.063 & -0.002 & 0.780 & 4.995 & 38.240 \\
\hline Metal & 0.024 & 0.128 & 0.001 & 0.269 & 3.124 & 1.818 \\
\hline Chemi & 0.004 & 0.030 & -0.001 & 0.529 & 5.712 & 50.526 \\
\hline Org-che & 0.015 & 0.110 & -0.001 & 0.541 & 6.034 & 61.835 \\
\hline Medi & 0.017 & 0.222 & -0.001 & 3.528 & 40.436 & 8646.957 \\
\hline Plastics & 0.024 & 0.155 & -0.001 & 0.179 & 4.494 & 14.079 \\
\hline Tex-fabs & 0.002 & 0.022 & -0.001 & 0.981 & 9.442 & 270.190 \\
\hline Iron & 0.016 & 0.098 & -0.001 & 0.346 & 3.563 & 4.756 \\
\hline Nonfme & 0.027 & 0.142 & -0.001 & -0.101 & 2.771 & 0.557 \\
\hline Mach & 0.002 & 0.012 & -0.001 & 1.251 & 4.713 & 54.798 \\
\hline \multirow[t]{2}{*}{ El-mach } & 0.003 & 0.039 & -0.001 & 3.623 & 29.068 & 4362.043 \\
\hline & \multicolumn{6}{|c|}{ Validation Sample } \\
\hline Toba & 0.013 & 0.055 & -0.005 & 1.816 & 5.352 & 37.475 \\
\hline Pulp & 0.032 & 0.154 & 0.003 & -0.544 & 3.267 & 2.510 \\
\hline Wood & 0.008 & 0.059 & -0.001 & 1.222 & 10.495 & 124.289 \\
\hline Metal & 0.018 & 0.082 & 0.001 & -0.503 & 3.010 & 2.019 \\
\hline Chemi & 0.002 & 0.015 & 0.001 & 0.476 & 3.840 & 3.220 \\
\hline Org-che & 0.014 & 0.077 & -0.002 & 0.466 & 4.737 & 7.773 \\
\hline Medi & 0.013 & 0.095 & -0.001 & -4.094 & 24.843 & 1088.363 \\
\hline Plastics & 0.021 & 0.078 & -0.001 & 0.382 & 2.101 & 2.784 \\
\hline Tex-fabs & 0.002 & 0.012 & -0.001 & -1.073 & 4.759 & 15.402 \\
\hline Iron & 0.013 & 0.071 & -0.001 & -0.021 & 3.757 & 1.151 \\
\hline Nonfme & 0.026 & 0.136 & 0.002 & 0.029 & 3.526 & 0.561 \\
\hline Mach & 0.002 & 0.010 & -0.001 & 1.177 & 6.593 & 36.914 \\
\hline El-mach & 0.002 & 0.011 & -0.001 & 0.036 & 3.357 & 0.267 \\
\hline
\end{tabular}


Note: the descriptive statistics for the above tables are, in column order: sample std. deviation, range, median, sample skewness, sample kurtosis and normality test.

Table 5. Linearity Tests: For Industry-level WPIs in Japan

\begin{tabular}{c|ccccccc|}
\cline { 2 - 7 } Industry WPI & Chemi & Food & Mach & Metal & Petrol & Textiles & Wood \\
\cline { 2 - 8 } F-test & 1.027 & 1.782 & 11.642 & 1.637 & 5.091 & 6.006 & 6.532 \\
p-value & 0.381 & 0.150 & 0.000 & 0.136 & 0.025 & 0.015 & 0.000 \\
\hline
\end{tabular}

Table 6. Linearity Tests: For Industry-level PPIs and CPIs in USA

\begin{tabular}{c|cccccc|} 
Industry PPI & Meat & Fruit & Beve & Metal & Chemi & Org-che \\
\cline { 2 - 7 } F-test & 0.369 & 1.758 & 0.168 & 0.334 & 0.093 & 0.074 \\
p-value & 0.775 & 0.144 & 0.683 & 0.917 & 0.760 & 0.785 \\
\cline { 2 - 7 } Industry PPI & Inor-che & Rubber & Nm-min & Me-mach & El-mach & Furni \\
\cline { 2 - 7 } F-test & 0.594 & 1.171 & 0.502 & 0.680 & 0.647 & 0.665 \\
p-value & 0.554 & 0.325 & 0.480 & 0.412 & 0.692 & 0.618 \\
\cline { 2 - 7 } Industry CPI & Mfl & Food. & Appa. & & & \\
\cline { 2 - 7 } F-test & 3.801 & 1.267 & 1.118 & & & \\
p-value & 0.013 & 0.272 & 0.359 & & & \\
\cline { 2 - 7 } & & & &
\end{tabular}

Table 7. Linearity Tests: For Industry-level PPIs in UK

\begin{tabular}{c|ccccccc|}
\cline { 2 - 8 } Industry PPI & Toba & Pulp & Wood & Metal & Chemi & Org-che & Medi. \\
\cline { 2 - 8 } F-test & 1.170 & 0.526 & 0.235 & 1.412 & 1.057 & 0.862 & 3.245 \\
p-value & 0.327 & 0.665 & 0.872 & 0.242 & 0.306 & 0.463 & 0.025 \\
\cline { 2 - 8 } Industry PPI & Plastics & Tex-fabs & Iron & Nonfme & Mach & El-mach & \\
\cline { 2 - 8 } F-test & 0.715 & 0.286 & 0.698 & 0.102 & 0.046 & 0.036 & \\
p-value & 0.544 & 0.835 & 0.555 & 0.959 & 0.829 & 0.848 & \\
\cline { 2 - 8 } & & & & & & &
\end{tabular}


Table 8. Forecasting Performance for WPIs in Japan

\begin{tabular}{|c|c|c|c|c|c|c|c|c|c|c|c|c|}
\hline \multirow[t]{3}{*}{ Industry } & \multicolumn{12}{|c|}{ Monthly Rolling Forecasts } \\
\hline & ARMA & SYS & VAR1 & VAR2 & ARMA & SYS & VAR1 & VAR2 & ARMA & SYS & VAR1 & VAR2 \\
\hline & \multicolumn{4}{|c|}{ One-month ahead } & \multicolumn{4}{|c|}{ Two-months ahead } & \multicolumn{4}{|c|}{ Three-months ahead } \\
\hline Chemi & 5.58 & 5.56 & 6.65 & 5.84 & 5.45 & 5.01 & 7.52 & 5.68 & 5.08 & 5.14 & 7.35 & 5.46 \\
\hline Food & 3.11 & 3.21 & 3.41 & 3.02 & 3.14 & 3.07 & 3.73 & 3.06 & 3.14 & 3.08 & 3.73 & 3.04 \\
\hline Mach & 5.23 & 5.57 & 5.81 & 5.80 & 5.47 & 5.18 & 5.72 & 5.59 & 5.13 & 5.21 & 5.85 & 5.18 \\
\hline Metal & 2.19 & 2.07 & 3.01 & 2.47 & 1.90 & 2.01 & 3.49 & 2.19 & 1.93 & 1.98 & 3.71 & 2.28 \\
\hline Petrol & 18.32 & 19.61 & 20.18 & 19.39 & 19.74 & 19.62 & 22.72 & 21.02 & 19.95 & 19.15 & 24.66 & 21.37 \\
\hline Textiles & 7.16 & 6.67 & 8.94 & 7.79 & 6.92 & 6.63 & 8.12 & 7.37 & 6.56 & 6.52 & 8.23 & 6.76 \\
\hline Wood & 5.55 & 6.15 & 8.01 & 6.01 & 6.73 & 6.39 & 10.67 & 7.23 & 6.98 & 6.41 & 10.89 & 7.52 \\
\hline
\end{tabular}

Table 9. Forecasting Performance for PPIs in USA

\begin{tabular}{|c|c|c|c|c|c|c|c|c|c|c|c|c|}
\hline \multirow[t]{3}{*}{ Industry } & \multicolumn{12}{|c|}{ Monthly Rolling Forecasts } \\
\hline & ARMA & SYS & VAR1 & VAR2 & ARMA & SYS & VAR1 & VAR2 & ARMA & SYS & VAR1 & VAR2 \\
\hline & \multicolumn{4}{|c|}{ One-month ahead } & \multicolumn{4}{|c|}{ Two-months ahead } & \multicolumn{4}{|c|}{ Three-months ahead } \\
\hline Meat & 14.96 & 14.54 & 27.87 & 22.54 & 14.85 & 14.55 & 26.18 & 21.14 & 14.86 & 14.54 & 29.95 & 22.70 \\
\hline Fruit & 1.78 & 1.98 & 3.31 & 2.62 & 1.82 & 1.90 & 3.25 & 2.55 & 1.85 & 2.00 & 2.95 & 2.48 \\
\hline Beve & 3.86 & 3.84 & 6.85 & 5.42 & 3.86 & 3.83 & 6.31 & 5.21 & 3.89 & 3.88 & 6.51 & 4.97 \\
\hline Metal & 3.39 & 3.54 & 10.92 & 5.49 & 3.57 & 3.71 & 14.95 & 5.85 & 3.76 & 3.88 & 20.37 & 6.53 \\
\hline Chemi & 5.92 & 5.81 & 7.88 & 5.99 & 6.23 & 5.97 & 8.63 & 5.94 & 6.38 & 6.12 & 8.19 & 5.96 \\
\hline Org-che & 17.05 & 16.14 & 24.18 & 16.67 & 17.59 & 15.72 & 26.32 & 17.65 & 17.61 & 15.97 & 23.86 & 18.23 \\
\hline Inor-che & 11.64 & 11.55 & 15.03 & 11.71 & 11.71 & 11.18 & 14.10 & 11.78 & 11.25 & 11.20 & 13.24 & 10.89 \\
\hline Rubber & 3.30 & 3.23 & 5.38 & 4.26 & 3.32 & 3.25 & 5.34 & 4.10 & 3.15 & 3.14 & 5.15 & 3.84 \\
\hline Nm-min & 2.26 & 2.30 & 5.11 & 3.14 & 2.26 & 2.32 & 4.48 & 3.14 & 2.26 & 2.28 & 4.50 & 2.94 \\
\hline Me-mach & 1.73 & 1.96 & 4.28 & 2.47 & 1.74 & 1.88 & 4.70 & 2.28 & 1.74 & 1.90 & 3.11 & 2.11 \\
\hline El-mach & 1.53 & 1.47 & 2.67 & 2.12 & 1.60 & 1.48 & 2.37 & 2.04 & 1.58 & 1.50 & 2.45 & 2.02 \\
\hline Furni & 1.32 & 1.31 & 3.30 & 1.93 & 1.33 & 1.32 & 2.62 & 1.66 & 1.29 & 1.28 & 2.84 & 1.75 \\
\hline
\end{tabular}


Table 10. Forecasting Performance for CPIs in USA

\begin{tabular}{|c|c|c|c|c|c|c|c|c|c|c|c|c|}
\hline \multirow[t]{3}{*}{ Industry } & \multicolumn{12}{|c|}{ Monthly Rolling Forecasts } \\
\hline & ARMA & SYS & VAR1 & VAR2 & ARMA & SYS & VAR1 & VAR2 & ARMA & SYS & VAR1 & VAR2 \\
\hline & \multicolumn{4}{|c|}{ One-month ahead } & \multicolumn{4}{|c|}{ Two-months ahead } & \multicolumn{4}{|c|}{ Three-months ahead } \\
\hline Mfl & 61.67 & 58.41 & 69.52 & 74.35 & 56.81 & 56.14 & 83.72 & 78.43 & 56.45 & 56.01 & 93.17 & 81.93 \\
\hline Food. & 1.81 & 1.92 & 7.74 & 3.29 & 1.84 & 2.06 & 6.38 & 3.25 & 1.86 & 2.09 & 4.67 & 3.15 \\
\hline Appa. & 22.49 & 15.04 & 16.77 & 11.62 & 21.97 & 14.94 & 15.76 & 10.87 & 22.57 & 22.27 & 15.78 & 10.93 \\
\hline
\end{tabular}

Table 11. Forecasting Performance for PPIs in UK

\begin{tabular}{|c|c|c|c|c|c|c|c|c|c|c|c|c|}
\hline \multirow[t]{3}{*}{ Industry } & \multicolumn{12}{|c|}{ Monthly Rolling Forecasts } \\
\hline & ARMA & SYS & VAR1 & VAR2 & ARMA & SYS & VAR1 & VAR2 & ARMA & SYS & VAR1 & VAR2 \\
\hline & \multicolumn{4}{|c|}{ One-month ahead } & \multicolumn{4}{|c|}{ Two-months ahead } & \multicolumn{4}{|c|}{ Three-months ahead } \\
\hline Toba & 13.66 & 13.56 & 22.19 & 18.66 & 13.62 & 13.59 & 21.75 & 18.14 & 13.67 & 13.61 & 19.74 & 18.01 \\
\hline Pulp & 29.96 & 28.56 & 34.84 & 30.09 & 31.39 & 29.61 & 35.33 & 30.55 & 35.06 & 32.45 & 35.06 & 32.74 \\
\hline Wood & 8.36 & 8.34 & 9.27 & 8.96 & 7.99 & 7.96 & 9.48 & 9.12 & 8.04 & 7.97 & 8.98 & 8.64 \\
\hline Metal & 18.02 & 18.07 & 20.37 & 19.63 & 18.05 & 18.32 & 19.06 & 18.88 & 17.97 & 18.37 & 18.48 & 18.26 \\
\hline Chemi & 2.87 & 2.79 & 4.16 & 3.58 & 3.01 & 2.84 & 3.87 & 2.94 & 3.09 & 2.89 & 3.89 & 3.20 \\
\hline Org-che & 14.24 & 13.60 & 14.86 & 14.72 & 14.79 & 13.82 & 15.21 & 14.09 & 14.88 & 13.93 & 15.83 & 14.66 \\
\hline Medi. & 13.43 & 14.43 & 17.87 & 16.48 & 13.33 & 14.48 & 18.31 & 15.23 & 13.33 & 14.51 & 17.46 & 15.10 \\
\hline Plastics & 19.88 & 20.04 & 20.02 & 17.15 & 22.00 & 21.91 & 22.38 & 18.26 & 21.53 & 21.43 & 23.93 & 19.65 \\
\hline Tex-fabs & 2.24 & 2.31 & 2.90 & 2.68 & 2.23 & 2.18 & 2.78 & 2.55 & 2.30 & 2.18 & 2.81 & 2.60 \\
\hline Iron & 13.47 & 13.00 & 14.61 & 14.09 & 14.27 & 13.78 & 16.39 & 15.08 & 14.30 & 13.83 & 16.42 & 15.47 \\
\hline Nonfme & 25.78 & 25.94 & 29.95 & 26.57 & 25.40 & 24.99 & 29.25 & 26.96 & 25.53 & 24.88 & 28.20 & 26.37 \\
\hline Mach & 1.82 & 1.67 & 2.51 & 2.12 & 1.82 & 1.67 & 2.53 & 2.12 & 1.81 & 1.67 & 2.38 & 1.99 \\
\hline El-mach & 2.50 & 2.55 & 3.79 & 3.27 & 2.49 & 2.39 & 3.86 & 3.19 & 2.49 & 2.41 & 3.81 & 2.96 \\
\hline
\end{tabular}


Table 12. Forecasting Performance for Non-linear WPIs in Japan

\begin{tabular}{|c|c|c|c|c|c|c|c|c|c|c|c|}
\hline \multirow[t]{3}{*}{ Industry } & \multicolumn{11}{|c|}{ Monthly Rolling Forecasts } \\
\hline & N1 & $\mathrm{N} 2$ & STAR & TAR & N1 & N2 & STAR & TAR & N1 & $\mathrm{N} 2$ & STAR \\
\hline & \multicolumn{4}{|c|}{ One-month ahead } & \multicolumn{4}{|c|}{ Two-months ahead } & \multicolumn{3}{|c|}{ Three-months ahead } \\
\hline Mach & 5.68 & 5.57 & 5.63 & 6.44 & 5.14 & 5.18 & 5.17 & & 5.12 & 5.21 & 5.19 \\
\hline Petrol & 20.21 & 19.63 & 21.06 & na & 20.28 & 19.61 & 21.11 & & 19.99 & 19.15 & 20.46 \\
\hline Textiles & 7.40 & 6.62 & 7.30 & 7.26 & 6.73 & 6.58 & 6.90 & & 6.89 & 6.53 & 7.17 \\
\hline Wood & 6.53 & 6.16 & 6.69 & 17.69 & 6.75 & 6.39 & 7.17 & & 6.81 & 6.41 & 7.11 \\
\hline
\end{tabular}

Table 13. Forecasting Performance for Non-linear PPI in UK

\begin{tabular}{|c|c|c|c|c|c|c|c|c|c|c|c|c|}
\hline \multirow[t]{3}{*}{ Industry } & \multicolumn{12}{|c|}{ Monthly Rolling Forecasts } \\
\hline & N1 & N2 & STAR & TAR & N1 & $\mathrm{N} 2$ & STAR & TAR & N1 & $\mathrm{N} 2$ & STAR & TAR \\
\hline & \multicolumn{4}{|c|}{ One-month ahead } & \multicolumn{4}{|c|}{ Two-months ahead } & \multicolumn{4}{|c|}{ Three-months ahead } \\
\hline Medi. & 20.13 & 14.24 & 13.64 & 17.20 & 20.02 & 14.16 & 13.65 & & 20.07 & 14.09 & 13.66 & \\
\hline
\end{tabular}

Note: In tables 12 and 13, N1 depicts RMSE values from naive ARMA model, N2 denotes RMSE values from naive SYSTEMs, STAR denotes RMSEs from non-linear STAR models and TAR denotes RMSEs from non-linear TAR models. 


\section{Appendix 2: Model choice results}

Table A2.1 Nested Model Testing for System I

\begin{tabular}{|c|c|c|c|c|}
\hline \multirow{2}{*}{$\begin{array}{l}\text { Country } \\
\text { Japan }\end{array}$} & Industry & $R 1$ is correct & $R 2$ is correct & $R 3$ is correct \\
\hline & Chemi & 52.788 & 93.992 & na \\
\hline \multirow{3}{*}{ Japan } & $\mathrm{p}$-value & 0.002 & 0.567 & na \\
\hline & Food & 54.057 & 129.918 & na \\
\hline & $\mathrm{p}$-value & 0.002 & 0.002 & na \\
\hline \multirow[t]{2}{*}{ Japan } & Mach & 46.112 & 72.193 & na \\
\hline & $\mathrm{p}$-value & 0.064 & 0.999 & na \\
\hline \multirow[t]{2}{*}{ Japan } & Metal & 70.017 & 33.745 & na \\
\hline & p-value & 0.000 & 0.999 & na \\
\hline \multirow[t]{2}{*}{ Japan } & Petrol & 55.121 & 61.439 & na \\
\hline & p-value & 0.001 & 0.997 & na \\
\hline \multirow[t]{2}{*}{ Japan } & Textiles & 165.985 & 115.564 & na \\
\hline & $\mathrm{p}$-value & 0.000 & 0.969 & na \\
\hline \multirow[t]{2}{*}{ Japan } & Wood & 63.177 & 69.462 & na \\
\hline & p-value & 0.000 & 0.995 & na \\
\hline \multirow[t]{2}{*}{ USA } & Mfl & 404.010 & 89.932 & na \\
\hline & p-value & 0.000 & 0.999 & na \\
\hline \multirow[t]{2}{*}{ USA } & Food. & 338.499 & 6.053 & na \\
\hline & $\mathrm{p}$-value & 0.000 & 0.999 & na \\
\hline \multirow[t]{2}{*}{ USA } & Appa. & 67.792 & 77.684 & na \\
\hline & $\mathrm{p}$-value & 0.000 & 0.888 & na \\
\hline
\end{tabular}


Table A2.2 Nested Model Testing for System II

\begin{tabular}{|c|c|c|c|c|}
\hline Country & Industry & $R 1$ is correct & $R 2$ is correct & $R 3$ is correct \\
\hline USA & Meat & 21.825 & na & 21.802 \\
\hline \multirow{3}{*}{ USA } & $\mathrm{p}$-value & 0.351 & na & 0.995 \\
\hline & Fruit & 13.735 & na & 41.308 \\
\hline & $\mathrm{p}$-value & 0.746 & na & 0.287 \\
\hline \multirow[t]{2}{*}{ USA } & Beve & 12.212 & na & 23.810 \\
\hline & p-value & 0.836 & na & 0.973 \\
\hline \multirow[t]{2}{*}{ USA } & Metal & 14.352 & na & 26.680 \\
\hline & $\mathrm{p}$-value & 0.763 & na & 0.485 \\
\hline \multirow[t]{2}{*}{ USA } & Chemi & 44.851 & 66.422 & na \\
\hline & $\mathrm{p}$-value & 0.001 & 0.059 & na \\
\hline \multirow[t]{2}{*}{ USA } & Org-che & 17.283 & na & 47.863 \\
\hline & $\mathrm{p}$-value & 0.635 & na & 0.214 \\
\hline \multirow[t]{2}{*}{ USA } & Inor-che & 21.748 & na & 18.696 \\
\hline & $\mathrm{p}$-value & 0.243 & na & 0.992 \\
\hline \multirow[t]{2}{*}{ USA } & Rubber & 21.686 & na & 27.366 \\
\hline & $\mathrm{p}$-value & 0.357 & na & 0.949 \\
\hline \multirow[t]{2}{*}{ USA } & Nm-min & 9.220 & na & 27.155 \\
\hline & $\mathrm{p}$-value & 0.980 & na & 0.983 \\
\hline \multirow[t]{2}{*}{ USA } & Me-mach & 7.252 & na & 68.739 \\
\hline & p-value & 0.995 & na & 0.001 \\
\hline \multirow{2}{*}{ USA } & El-mach & 9.271 & na & 30.111 \\
\hline & p-value & 0.979 & na & 0.914 \\
\hline \multirow[t]{2}{*}{ USA } & Furni & 8.299 & na & 42.688 \\
\hline & p-value & 0.989 & na & 0.398 \\
\hline
\end{tabular}


Table A2.3 Nested Model Testing for System II

\begin{tabular}{|c|c|c|c|c|}
\hline Country & Industry & $R 1$ is correct & $R 2$ is correct & $R 3$ is correct \\
\hline \multirow[t]{2}{*}{ UK } & Toba & 51.146 & na & 50.419 \\
\hline & $\mathrm{p}$-value & 0.351 & na & 0.999 \\
\hline \multirow[t]{2}{*}{ UK } & Pulp & 64.107 & 46.194 & na \\
\hline & p-value & 0.000 & 0.464 & na \\
\hline \multirow[t]{2}{*}{ UK } & Wood & 19.018 & na & 10.727 \\
\hline & p-value & 0.088 & na & 0.978 \\
\hline \multirow[t]{2}{*}{ UK } & Metal ores & 24.510 & 23.351 & na \\
\hline & p-value & 0.017 & 0.612 & na \\
\hline \multirow[t]{2}{*}{ UK } & Chemi & 38.741 & 49.647 & na \\
\hline & $\mathrm{p}$-value & 0.003 & 0.258 & na \\
\hline \multirow[t]{2}{*}{ UK } & Org-che & 18.275 & na & 37.008 \\
\hline & p-value & 0.107 & na & 0.012 \\
\hline \multirow[t]{2}{*}{ UK } & Medi. & 18.946 & na & 19.563 \\
\hline & p-value & 0.395 & na & 0.994 \\
\hline \multirow[t]{2}{*}{ UK } & Plastics & 27.529 & na & 40.591 \\
\hline & p-value & 0.069 & na & 0.237 \\
\hline \multirow[t]{2}{*}{ UK } & Tex-fabs & 16.874 & na & 26.804 \\
\hline & p-value & 0.531 & na & 0.838 \\
\hline \multirow[t]{2}{*}{ UK } & Iron \& Steel & 24.781 & na & 39.093 \\
\hline & p-value & 0.131 & na & 0.252 \\
\hline \multirow[t]{2}{*}{ UK } & Nonfme & 22.944 & 20.027 & na \\
\hline & p-value & 0.028 & 0.829 & na \\
\hline \multirow[t]{2}{*}{ UK } & Mach & 11.898 & na & 39.744 \\
\hline & p-value & 0.852 & na & 0.194 \\
\hline \multirow[t]{2}{*}{ UK } & El-mach & 32.678 & na & 45.650 \\
\hline & p-value & 0.111 & na & 0.528 \\
\hline
\end{tabular}




\section{Appendix 3: Industry-level import data description}

\section{Japan: Import prices are taken for the following industries}

Chemicals (denoted by 'Chemi' in the tables)

Foodstuffs and Feedstuff (denoted by 'Food' in the tables)

Machinery and Equipment (denoted by 'Mach' in the tables)

Metals and Related Products (denoted by 'Metal' in the tables)

Petroleum, Coal and Natural Gas (denoted by 'Petrol' in the tables)

Textiles (denoted by 'Textiles' in the tables)

Wood, Lumber and Related Products (denoted by 'Wood' in the tables)

\section{USA: Import prices are taken for the following industries, numbers on left corre- spond to SITC}

01 Meat and meat preparations (denoted by 'Meat' in the tables; subcategory of SITC category "Food and live animals")

05 Vegetables, fruit and nuts, fresh or dried (denoted by 'Fruit' in the tables; subcategory of SITC category "Food and live animals")

11 Beverages (denoted by 'Beve' in the tables; subcategory of SITC category "Beverages and Tobacco") 28 Metalliferous ores and metal scrap (denoted by 'Metal' in the tables; subcategory of SITC category "Crude materials, inedible, except fuels")

5 Chemicals and related products, n.e.s (denoted by 'Chemi' in the tables)

51 Organic chemicals (denoted by 'Org-che' in the tables; subcategory of SITC category "Chemicals and related products")

52 Inorganic chemicals (denoted by 'Inor-che' in the tables; subcategory of SITC category "Chemicals and related products")

62 Rubber manufactures, n.e.s (denoted by 'Rubber' in the tables; subcategory of SITC category "Manufactured goods classified chiefly by materials") 
66 Non-metallic mineral manufactures (denoted by 'Nm-min' in the tables; subcategory of SITC category "Manufactured goods classified chiefly by materials")

73 Metalworking machinery (denoted by 'Me-mach' in the tables; subcategory of SITC category "Machinery and Transport Equipment")

77 Electrical machinery and equipment (denoted by 'El-mach' in the tables; subcategory of SITC category "Machinery and Transport Equipment")

82 Furniture and parts thereof (denoted by 'Furni' in the tables; subcategory of SITC category "Miscellaneous manufactured articles")

UK: Import prices are taken for the following industries, numbers on left correspond to SITC

12 Tobacco (denoted by 'Toba' in the tables; subcategory of SITC category "Beverages and Tobacco") 25 Pulp and waste paper (denoted by 'Pulp' in the tables; subcategory of SITC category "Crude Materials") 24 Wood and cork (denoted by 'Wood' in the tables; subcategory of SITC category "Crude Materials") 27 Metal ores (denoted by 'Metal ores' in the tables; subcategory of SITC category "Crude Materials") 5 Chemicals (denoted by 'Chemi' in the tables)

51 Organic chemicals (denoted by 'Org-che' in the tables; subcategory of SITC category "Chemicals") 54 Medicinal products (denoted by 'Medi.' in the tables; subcategory of SITC category "Chemicals") 57+58 Plastics (denoted by 'Plastics' in the tables; subcategory of SITC category "Chemicals") 65 Textile fabrics (denoted by 'Tex-fabs' in the tables; subcategory of SITC category "Manufactures") 67 Iron and Steel (denoted by 'Iron' in the tables; subcategory of SITC category "Manufactures") 68 Non-ferrous metals (denoted by 'Nonfme' in the tables; subcategory of SITC category "Manufactures") 7 Machinery and Transport Equipment (denoted by 'Mach' in the tables)

$716+75+76+77$ Electrical machinery (denoted by 'El-mach' in the tables; subcategory of SITC category "Machinery and Transport Equipment") 